\title{
Mutation analysis of the WNT4 gene in Han Chinese women with premature ovarian failure
}

\author{
Beili Chen ${ }^{1 \dagger}$, Peisu Suo ${ }^{2,3+}{ }^{\dagger}$, Binbin Wang ${ }^{2,3}$, Jing Wang ${ }^{2,3}$, Lu Yang ${ }^{1}$, Sirui Zhou ${ }^{2,3}$, Ying Zhu' ${ }^{1}$ Xu Ma ${ }^{2,3,4}$ and \\ Yunxia Cao ${ }^{1 *}$
}

\begin{abstract}
Background: The WNT4 gene plays an important role in female sex determination and differentiation. It also contributes to maintaining of the ovaries and the survival of follicles.

Methods: We sequenced the coding region and splice sites of WNT4 in 145 Han Chinese women with premature ovarian failure (POF) and 200 healthy controls.

Results: Only one novel variation, in Exon 2 (195C > T), was detected among the women with POF. However, this synonymous variation did not result in a change in amino acid sequence (65 Asp > Asp). No further variants were found in any of the samples.

Conclusion: Although we cannot provide any evidence that it is a possible disease-causing gene, this study is the first attempt to investigate the possible role of WNT4 in Han Chinese women with POF.
\end{abstract}

\section{Background}

Premature ovarian failure (POF) is a rare disease that severely affects the reproductive health and endocrine balance of $1 \%$ of all women [1]. It is characterized by abnormal follicular genesis, development or apoptosis. POF presents clinically as primary amenorrhea in women with abnormal prepubertal onset, or as spontaneous secondary amenorrhea in women with premature depletion of ovarian follicles/arrested folliculogenisis. The etiological factors and pathogenesis of POF are extremely heterogeneous. As a severe complication in patients after treatments for ovarian neoplasms or autoimmune diseases, the damage caused by iatrogenic factors (surgery, chemotherapy, radiations) accounts for many cases. However, the causes are still unclear in most cases of POF (especially idiopathic form). Genetic factors are known to provide a significant etiological component in recent studies. Apart from studying $\mathrm{X}$ chromosome deletions and $\mathrm{X} /$ autosome translocations in patients, research has focused increasingly on some

\footnotetext{
* Correspondence: ayszaysz@163.com

† Contributed equally

'Reproductive Medicine Center, First Affiliated Hospital, Anhui Medical University, Hefei, PR China Full list of author information is available at the end of the article
}

candidate genes involved in ovarian failure in animal models, such as Fshr and Foxl2 [2].

Wnt4, which encodes a secreted extracellular signaling protein, is known to be involved in multiple developmental processes, such as the formation of the kidney, adrenal gland and gonads [3-5]. Many studies have demonstrated that this gene plays an important role in mammalian female sexual differentiation. It is downregulated in the testis and upregulated in the ovary at 11.5 days post-coitum in the mouse by activating Frizzled-4, expressed on luteal cell membranes to activate distinct signaling cascades [5]. The inactivation of Wnt4 led to ovarian dysgenesis with early production of testosterone by mesenchymal cells and formation of male internal genitalia, including testicular tubules and spermatogonia in $\mathrm{XX}$ mice [6,7].

Recently, attention has been paid to the contribution of WNT4 for the maintenance of ovaries and survival of follicles in the mouse and humans. WNT4 is expressed in the bipotential embryonic gonad of both sexes, and increases when small primary follicles are formed during mid-pregnancy. Vainio et al. observed that the number of oocytes in Wnt4 mutant mouse ovaries was abnormally low at birth [5]. Although Wnt4 has not been shown to affect the number of primordial germ cells in the undifferentiated gonad, it is thought to act as an
C Biomed Central 
oocyte survival factor during female embryogenesis [8]. Compared with wild-type mice, Wnt4 deficient mice had a markedly enhanced rate of oocyte apoptosis $[9,10]$. There are two oocyte-specific transcriptional factors, FIGLA and NOBOX, acting downstream of WNT4 signaling, which are associated with POF $[11,12]$. Therefore, we carried out mutational screening of the WNT4 gene in Han Chinese women with POF.

\section{Methods}

\section{Patient information}

One hundred and forty-five unrelated women with idiopathic POF and 200 healthy controls were recruited from the Reproductive Medical Center of the First Affiliated Hospital, Anhui Medical University, P. R. China. All the participants were the Han people (China's main nationality) in three generations without minority and signed the informed consent. The diagnostic criteria for POF were defined as follows. (1) Women showed primary amenorrhea or spontaneous secondary amenorrhea for more than 6 months before the age of 40 years. (2) Repeated elevated levels of follicle stimulating hormone ( $\mathrm{FSH} ;>30 \mathrm{mIU} / \mathrm{mL}$ ) and low plasma estradiol levels. (3) Normal karyotype 46, XX. (4) No history of pelvic surgery, chemotherapy or autoimmune diseases. All the healthy controls had regular menstrual cycles, normal FSH levels and denied any history of a medical disease related to ovarian function.

The mean age of patients with POF at the time of study, menarche and amenorrhea were $30.4 \pm 6.51$ years, $14.5 \pm 1.98$ years and $25.9 \pm 6.90$ years, respectively. The mean age of the controls was $31.2 \pm 4.50$ years at screening (range 21-52). All subjects had a normal growth history and weight based on a physical examination. Patients with POF had a mean serum FSH level of $74.92 \pm 30.52 \mathrm{mIU} / \mathrm{mL}$ ( $\mathrm{LH} 32.78 \pm 15.75 \mathrm{mIU} /$ $\mathrm{mL}$ ) and presented with primary amenorrhea (17, $11.7 \%)$ or secondary amenorrhea $(128,88.3 \%)$, accompanied by some endocrine disorders such as hectic fever, night sweating, anxiety, fatigue or vaginal dryness. No patient was found with hyperandrogenism. Ultrasonography showed that most of the ovaries in women with POF were smaller than normal with few growing follicles or even no follicles. In women with primary amenorrhea, gonadal dysgenesis was documented by the finding of streak ovaries. The possibilities of other causes of primary amenorrhea, such as congenital absence of the vagina, androgen insensitivity syndrome, and Turner's syndrome, had already been ruled out through gynecological examinations, transvaginal ultrasound checks, and endocrine and chromosomal studies.

\section{DNA analysis}

Genomic DNA was extracted from $200 \mu \mathrm{l}$ samples of peripheral blood leukocytes using TIANamp Blood DNA kits (TIANGEN, Beijing, P.R. China). The entire coding region and splice sites of the WNT4 gene (comprising 5 exons) were divided into four parts to be amplified by polymerase chain reaction (PCR) using primers designed by Primer 5.0 software (http://www.premierbiosoft.com/ primerdesign/index.html). The sequences of primers and specific conditions for PCR amplification are available on request. All the PCR products were directly sequenced using an ABI 3730XL automated sequencer (Applied Biosystems, Foster City, CA, USA) according to the manufacturer's protocol.

\section{Results}

PCR was performed to amplify the coding region of WNT4 and the sequencing data was collected and analyzed for all cases and controls. Only one novel variation was detected among the 145 patients with POF. This synonymous variation in Exon $2(195 \mathrm{C}>\mathrm{T})$, which was not identified in the control population, did not result in a change in amino acid sequence (65 Asp > Asp). No further variants were found in any of the samples.

\section{Discussion}

Apart from the accepted view that WNT4 is a key regulator of gonadal determination and differentiation, its mRNA and protein are present in human ovaries during fetal development and at different stages of follicular development in adult ovaries [10]. Some functional analyses revealed that deficiencies in the WNT4 gene might affect the development of ovaries and follicles. Vainio et al. observed that the ovaries of Wnt4 mutant female mice had only a few degenerating oocytes [5]. Yao et al. found that germ cells in the ovarian cortex were almost completely absent in both Wnt4 and Fst null gonads and concluded that Wnt4 might play a critical role in maintaining germ cell survival in the ovary [9]. Similarly, Jääskeläinen et al. also revealed that Wnt4-deficient mice had a markedly enhanced rate of oocyte apoptosis [10].

Based on the above-mentioned studies and views, researchers began to study this gene from different aspects in human diseases, mainly involving Müllerian Duct abnormalities. A French collaborative study identified a new L12P mutation with Exon 1 of the WNT4 gene from a patient who presented with uterine hypoplasia and follicle depletion [13]. Biason-Lauber et al. also found that one girl with absence of a uterus, androgen excess and lack of follicles in her left ovary carried a novel loss-of-function dominant negative mutation in WNT4 [14]. Moreover, a homozygous missense mutation in the human WNT4 gene was identified in a novel autosomal-recessive syndrome SERKAL which consists of female to male sex reversal and renal, adrenal, and lung dysgenesis and is associated with additional 
developmental defects [15]. Therefore, we tried to determine whether Han Chinese women with POF might show a genetic background linked to the WNT4 gene. However, we did not observe any causal variant: only a silent mutation. Wnt genes have been highly conserved throughout evolution and play pivotal roles in a wide variety of physiological events during embryogenesis. We supposed that this conservatism and importance might determine the stability of the WNT4 gene. In addition, Jääskeläinen also pointed towards species-specific differences in the expression patterns of Wnt4 when comparing the results from mice and humans [10].

In conclusion, this study was the first attempt to investigate the possible role of WNT4 gene in Han Chinese women with POF, although we could not provide any evidence that it caused the disease. Therefore, more samples from different populations should be analyzed.

\section{Acknowledgements}

We are grateful to all the women who agreed to participate in our study This work was supported by grants from the National Basic Research Program of China (973 project 2007CB947403) and the National Natural Science Foundation of China (30973197).

\section{Author details}

${ }^{1}$ Reproductive Medicine Center, First Affiliated Hospital, Anhui Medical University, Hefei, PR China. ${ }^{2}$ National Research Institute for Family Planning, Beijing, 100081, PR China. ${ }^{3}$ Graduate School, Peking Union Medical College, Beijing, PR China. ${ }^{4}$ World Health Organization Collaborating Centre for Research in Human Reproduction, Beijing, PR China.

\section{Authors' contributions}

$B C, Y L$ and $Y Z$ collected all samples and performed the clinical tests. PS and JW carried out the molecular genetic studies. BC and SZ drafted the manuscript. BW, XM and YC participated in its design and coordination and helped to draft the manuscript. All authors read and approved the final manuscript.

\section{Competing interests}

The authors declare that they have no competing interests.

Received: 23 October 2010 Accepted: 30 May 2011

Published: 30 May 2011

\section{References}

1. Beck-Peccoz P, Persani L: Premature ovarian failure. Orphanet J Rare Dis 2006, 1:9.

2. Skillern A, Rajkovic A: Recent developments in identifying genetic determinants of premature ovarian failure. Sex Dev 2008, 2(4-5):228-243.

3. Stark K, Vainio S, Vassileva G, McMahon AP: Epithelial transformation of metanephric mesenchyme in the developing kidney regulated by Wnt4. Nature 1994, 372(6507):679-683.

4. Heikkila M, Peltoketo H, Leppaluoto J, Ilves M, Vuolteenaho O, Vainio S: Wnt-4 deficiency alters mouse adrenal cortex function, reducing aldosterone production. Endocrinology 2002, 143(11):4358-4365.

5. Vainio S, Heikkila M, Kispert A, Chin N, McMahon AP: Female development in mammals is regulated by Wnt-4 signalling. Nature 1999, 397(6718):405-409.

6. Heikkila M, Prunskaite R, Naillat F, Itaranta P, Vuoristo J, Leppaluoto J, Peltoketo $\mathrm{H}$, Vainio $\mathrm{S}$ : The partial female to male sex reversal in Wnt-4deficient females involves induced expression of testosterone biosynthetic genes and testosterone production, and depends on androgen action. Endocrinology 2005, 146(9):4016-4023.
7. Ottolenghi C, Pelosi E, Tran J, Colombino M, Douglass E, Nedorezov T, Cao A, Forabosco A, Schlessinger D: Loss of Wnt4 and Foxl2 leads to female-to-male sex reversal extending to germ cells. Hum Mol Genet 2007, 16(23):2795-2804

8. Heikkila M, Peltoketo $H$, Vainio $S$ : Wnts and the female reproductive system. J Exp Zool 2001, 290(6):616-623.

9. Yao HH, Matzuk MM, Jorgez CJ, Menke DB, Page DC, Swain A, Capel B: Follistatin operates downstream of Wnt4 in mammalian ovary organogenesis. Dev Dyn 2004, 230(2):210-215.

10. Jaaskelainen $M$, Prunskaite-Hyyrylainen $R$, Naillat $F$, Parviainen $H$, Anttonen M, Heikinheimo M, Liakka A, Ola R, Vainio S, Vaskivuo TE, et al: WNT4 is expressed in human fetal and adult ovaries and its signaling contributes to ovarian cell survival. Mol Cell Endocrino/ 317(1-2):106-111.

11. Bayne RA, Martins da Silva SJ, Anderson RA: Increased expression of the FIGLA transcription factor is associated with primordial follicle formation in the human fetal ovary. Mol Hum Reprod 2004, 10(6):373-381.

12. Qin Y, Choi Y, Zhao H, Simpson JL, Chen ZJ, Rajkovic A: NOBOX homeobox mutation causes premature ovarian failure. Am J Hum Genet 2007, 81(3):576-581.

13. Philibert $\mathrm{P}$, Biason-Lauber A, Rouzier R, Pienkowski C, Paris F, Konrad D, Schoenle $E$, Sultan C: Identification and functional analysis of a new WNT4 gene mutation among 28 adolescent girls with primary amenorrhea and mullerian duct abnormalities: a French collaborative study. J Clin Endocrinol Metab 2008, 93(3):895-900.

14. Biason-Lauber A, De Filippo G, Konrad D, Scarano G, Nazzaro A Schoenle EJ: WNT4 deficiency-a clinical phenotype distinct from the classic Mayer-Rokitansky-Kuster-Hauser syndrome: a case report. Hum Reprod 2007, 22(1):224-229.

15. Mandel H, Shemer R, Borochowitz ZU, Okopnik M, Knopf C, Indelman M, Drugan A, Tiosano D, Gershoni-Baruch R, Choder M, et al: SERKAL syndrome: an autosomal-recessive disorder caused by a loss-of-function mutation in WNT4. Am J Hum Genet 2008, 82(1):39-47.

doi:10.1186/1477-7827-9-75

Cite this article as: Chen et al:: Mutation analysis of the WNT4 gene in Han Chinese women with premature ovarian failure. Reproductive Biology and Endocrinology 2011 9:75.

\section{Submit your next manuscript to BioMed Central and take full advantage of:}

- Convenient online submission

- Thorough peer review

- No space constraints or color figure charges

- Immediate publication on acceptance

- Inclusion in PubMed, CAS, Scopus and Google Scholar

- Research which is freely available for redistribution 